Artigos

Volume 9 - 2019|n. 17

\title{
Quem são os professores que chegam à aposentadoria? Uma aproximação a partir dos dados da RAIS de professores da Educação Básica no Estado do Paraná
}

\author{
Andréa Barbosa Gouveia \\ Universidade Federal do Paraná (UFPR), Curitiba/PR - Brasil
}

\section{Resumo}

O debate sobre a profissão docente implica considerações sobre as condições de recrutamento, a atratividade da carreira, as condições de fixação do professor na carreira. Sendo assim, o presente artigo analisa a questão do direito à aposentadoria. Compreender as condições nas quais os professores terminam suas carreiras pode ser outra maneira de considerar a apreciação do professor em diferentes sistemas educacionais. A partir desses elementos, o trabalho propõe uma reflexão sobre os professores que chegam à aposentadoria, tomando como caso empírico os professores das redes públicas do Paraná, em dois anos-chave. A fonte de dados é a Relação Anual de Informações Sociais (RAIS) e o tratamento metodológico quantitativo propõe analisar quem são os professores aposentados considerando a idade, tempo de serviço, salário e qualificação.

Palavras-chave: Política Educacional. Remuneração de Professores. Envelhecimento. Aposentadoria.

\section{Who are the teachers who retire? A reading of the data of the Annual Social Information Report of K-12 education teachers from the state of Paraná}

\begin{abstract}
The debate about the teaching profession implies considerations regarding the conditions of recruitment, career's attractiveness, conditions of teacher fixing in the career and, in this article, it shows the question of the right to retirement. Understanding the circumstances under which these teachers finish their careers can be another way of considering the teacher appreciation in different education systems. From these elements, this paper proposes a reflection on the teachers who reach at the retirement taking as empirical case the teachers of the public networks of the state of Paraná in two key years. The data source is the RAIS and the quantitative methodological treatment proposes to analyze who are the retired teachers considering age, length of service, salary and qualification.
\end{abstract}

Keywords: Educational Policy. Teacher Remuneration. Ageing. Retirement. 
Quem são os professores que chegam à aposentadoria?

\section{Introdução}

O debate sobre aposentadoria não é um tema comum nas discussões sobre valorização docente. A proposta deste artigo é analisar o tema da chegada à aposentadoria como um elemento que compõe o desafio da valorização docente. Para isso, parte de algumas constatações: as análises sobre profissão docente têm implicado considerações sobre as condições de ingresso, atratividade (CASSETARI, 2010; SOUZA; ABREU, 2016) e sobre condições de fixação do professor nas carreiras (MORDUCHOWICZ, 2003; HARRYS, 2007). Anualmente, um conjunto de professores experientes alcança o direito à aposentadoria. Compreender em que condições estes sujeitos terminam a carreira e conquistam o direito à aposentadoria pode ser uma outra forma de considerar o sentido da atratividade e da capacidade de retenção na carreira nas diferentes redes de ensino. $O$ debate sobre as regras do sistema previdenciário brasileiro, em curso atualmente, problematiza a perspectiva de aposentadoria especial de professores e aprofunda as mudanças, já realizadas desde 2003, na previdência de servidores públicos. As mudanças constitucionais de 2003 e de 2004 quebraram a isonomia entre servidores públicos da ativa e aposentados, ao fixar que os servidores públicos podem se aposentar com $80 \%$ da média aritmética das maiores remunerações recebidas (RAFANHIM, 2013). Tal mecanismo implica alteração nas formas de progressão previstas nos planos de carreira, evidenciando que, salários iniciais baixos, além de não atraírem os estudantes para a profissão (GATTI, 2009), ainda passam a diminuir as perspectivas de uma aposentadoria digna. A partir desses elementos, propõe-se uma reflexão sobre quem são os professores que chegam à aposentadoria.

Para essa reflexão, toma-se como caso empírico os professores das redes públicas do Estado do Paraná em dois anos chave: 2008 e 2016. A questão proposta é de compreender quem são esses professores que permaneceram nas redes de ensino, considerando a idade, o tempo de serviço, a remuneração e a qualificação. Trata-se de pensar como o professor chega no momento da aposentadoria, considerando que trajetória de carreira foi possível e, se, no momento da aposentadoria, evidencia-se ou não a promessa da valorização docente. Observar dois momentos (2008 e 2016) agrega aos objetivos do artigo a problematização sobre se, nesse período, é possível identificar alterações no perfil do professor que termina a carreira nas redes públicas e levantar elementos para discutir a pertinência, ou não, de novas alterações nas regras de aposentadoria, considerando os efeitos que esse dispositivo tem no percurso das carreiras, portanto, os efeitos no tempo do professor na ativa.

Para o desenvolvimento do estudo, utilizou-se como fonte empírica os dados da Relação Anual de Informações Sociais (RAIS) do Ministério do Trabalho de 2016, ano mais recente disponível, e 2008, ano da aprovação do Piso Salarial Profissional Nacional (PSPN) para o magistério. A proposta não é discutir a política do PSPN, mas fixar um ano que marca uma política de promessa de valorização da remuneração de professores no Brasil.

Sobre o uso da RAIS para discutir as condições de remuneração de professores, cabem alguns destaques quanto à natureza da fonte de dados. A RAIS é um registro administrativo que foi "[...] criada com a finalidade de suprir as necessidades de controle, de estatísticas e de informações às entidades governamentais da área social" (BRASIL; MTE, 2018), especificamente sobre o mercado formal de trabalho, e é preenchida pelos empregadores. No setor público, estudos anteriores (FERNANDES; GOUVEIA; BENINI, 2012) indicavam 
problemas com o volume de informações fornecidas pelos empregadores públicos municipais e estaduais no âmbito da RAIS. O trabalho, com os microdados da RAIS disponibilizados na última década pelo Ministério do Trabalho e Emprego, parece conter um volume de dados que indica avanços em termos da representatividade do setor público.

No âmbito da RAIS, são declarados vínculos de empregos, portanto, para cada vínculo de emprego um mesmo professor poderá ter um registro diferente. Tendo em consideração essas duas ressalvas metodológicas, sobre eventuais ausências de dados e sobre a natureza administrativa da informação, destaca-se, por outra parte, que a RAIS apresenta a vantagem de informar a condição do vínculo de emprego ao longo do ano civil. Assim, é possível identificar quais vínculos foram desligados ao longo de um ano, e, entre as causas do desligamento, identifica-se o evento aposentadoria. Essa informação permite o debate aqui proposto.

\section{Alguns elementos iniciais para o debate sobre aposentadoria docente}

Tenti Fanfani (2005), ao analisar as condições da profissão docente em países da América do Sul, destaca que, para compreender quem são os docentes, é preciso considerar as diferentes exigências legais, formais e sociais que conformam a profissão docente. $O$ autor analisa dados da Argentina, Uruguai, Peru e Brasil e destaca que os professores podem chegar a cumprir as condições de aposentadoria mais cedo que outras carreiras profissionais, o que se explica por aspectos como a presença feminina intensa e as trajetórias de formação variadas. Considerando isso como tendência, pode-se considerar os efeitos no próprio desenvolvimento da carreira, ou seja, chegar mais cedo à aposentadoria relaciona-se potencialmente com perspectivas de chegar mais cedo ao final da carreira de professor.

Estudo da OCDE (2017) evidencia diferenças importantes entre os países quanto ao topo das carreiras docentes. Enquanto na Grécia, Hungria e Espanha os professores levam até 35 anos para chegar aos mais altos salários, na Austrália, no Reino Unido e na Nova Zelândia, por exemplo, o topo pode ser conquistado em menos de 10 anos (OCDE; UNESCO, 2017, p. 366). Pesquisa recente sobre a percepção de professores sobre sua qualidade de vida no Brasil identificou que os professores têm, entre suas preocupações, remunerações baixas após a aposentadoria, e essa preocupação amplia o sentimento de insatisfação profissional (GROCHOSKA, 2015). Em outro viés, pesquisas do âmbito da economia têm medido a relação entre os ganhos ao longo da vida laboral e benefícios de aposentadoria de professores e professoras no setor público e no setor privado. Apesar de evidências de maior longevidade das mulheres e aposentadoria com menor idade e tempo de contribuição, isso não tem compensado desigualdades salariais ao longo das carreiras (BECKER; KASSOUF, 2012). Esse conjunto de argumentos dispersos na literatura parece permitir tomar a aposentadoria como uma questão que compõe as disputas pela profissionalização docente.

A definição do que é a profissionalização incorpora alguns elementos fortes do processo de formação antes do ingresso na profissão e dos desdobramentos de reconhecimento como profissional ao longo da trajetória. A definição de Oliveira (2010, p. 19) tem esse sentido:

Profissionalização do magistério pode ser compreendida como um processo de construção histórica que varia com o contexto socioeconômico a que está submetida, mas que, sobretudo, tem definido tipos de formação e especialização, de carreira e remuneração para um determinado grupo social que vem crescendo e consolidando-se. 
Se a disputa pela profissionalização implica formação especializada, carreira específica e reconhecimento via remuneração, pode incorporar também a perspectiva de poder finalizar o ciclo profissional com aposentadoria específica. No caso brasileiro, pode-se reconhecer esse argumento no debate de Ferreira Jr. (2013), ao analisar a trajetória de defesa do direito à aposentadoria especial durante o processo de redemocratização protagonizado pela Confederação de Professores do Brasil (CPB):

A conquista da aposentadoria aos 25 anos de serviço não representou apenas um ponto de inflexão na trajetória político sindical da CPB, deslocando-a da órbita de influência ideológica da ditadura militar para a esfera de atuação da sociedade civil brasileira que reivindicava o Estado de direito democrático. A aposentadoria aos 25 anos representava também o próprio processo de transformação da categoria social dos professores públicos em protagonistas sociais com plena consciência histórica sobre seu próprio fazer profissional. Assim, podemos considerar que a conquista desta demanda implicou no reconhecimento da nova identidade profissional, que reverberou tanto da Lei 5.540/68 quanto da Lei 5692/71, que a categoria dos professores públicos adquiriu durante o processo de expansão quantitativa da escola pública obrigatória de oito anos. Assim, a aposentadoria aos 25 anos significou um dos importantes elementos da profissionalização dos professores públicos no transcorrer da transição que se operou nos anos 1970 [...] (FERREIRA JR., 2013, p. 163-164).

Essa articulação entre o direito à aposentadoria e a identidade profissional parece interessante, especialmente para compreender esse lugar do magistério no serviço público, diferenciado do próprio servidor público, assim como diferenciado de outros trabalhadores em geral. O magistério tem carreira, remuneração, mas também mantém um lugar "especial" conferido pelo reconhecimento de que precisa de condições específicas de aposentadoria que decorrem, ou potencialmente poderiam decorrer, da natureza de seu trabalho. Talvez seja um pouco exagerado seguir Ferreira Jr. no argumento de que os professores passaram a ser protagonistas sociais com plena consciência histórica sobre seu próprio fazer, porém inegavelmente parece forte $\mathrm{o}$ argumento do autor de que a identidade profissional do professor brasileiro conforma-se incorporando esta ideia de que a aposentadoria especial reconhece as agruras do trabalho, ou, de forma mais positiva, reconhece a distinção da profissão em relação a outras.

Em termos legais, a conquista da CPB significou uma Emenda à Constituição Federal de 1969, que regulou a aposentadoria especial de professores nos seguintes termos: "[...] a aposentadoria para o professor após 30 anos e, para a professora, após 25 anos de efetivo exercício em funções de magistério, com salário integral" (Redação da pela Emenda Constitucional $n^{\circ} 18$, de 1981; BRASIL, 1981). A constituição de 1988 ratificou essa posição no artigo 40, na sua redação original. A questão foi inserida como inciso do artigo que se referia ao conjunto dos servidores públicos, que especifica a condição dos professores que poderiam aposentar-se "[...] aos trinta anos de efetivo exercício em funções de magistério, se professor, e vinte e cinco, se professora, com proventos integrais" (BRASIL, 1988). Essa redação foi alterada com a Emenda Constitucional $n^{\circ} 20$, em 1998, que definiu a aposentadoria especial apenas para professores da educação básica:

Os requisitos de idade e de tempo de contribuição serão reduzidos em cinco anos, em relação ao disposto no $\S 1^{\circ}$, III, 'a', para o professor que comprove exclusivamente tempo de efetivo exercício das funções de magistério na educação infantil e no ensino 
Quem são os professores que chegam à aposentadoria?

fundamental e médio (Redação dada pela Emenda Constitucional $n^{\circ} 20$, de 15/12/98) (BRASIL, 1998).

Essa disputa em relação à abrangência da aposentadoria especial em relação ao magistério em geral, ou especificamente ao magistério na educação básica, tensiona a ideia de que o "especial" decorre da natureza do trabalho, a não ser que se considere que há especificidades diferentes entre o trabalho docente na educação básica e no ensino superior.

Pode-se argumentar em duas direções distintas aqui, por um lado, o trabalho docente no ensino superior público incorpora a dimensão da pesquisa, portanto, poderíamos afirmar que há uma diferença entre o que é a profissão docente brasileira na educação básica e no ensino superior, o que justificaria diferenças entre os requisitos de valorização profissional. Entretanto, a incorporação da aposentadoria especial não resolveu, no caso da educação básica, um conjunto de elementos de condições de trabalho que desvalorizam a profissão docente, seja pela intensificação das atividades, seja pela manutenção de patamares de remuneração abaixo de outros profissionais de mesma formação, o que tem reiterado as denúncias de precarização do trabalho docente no País. Assim, não parece adequado tomar aqui um a priori de que o trabalho docente na educação básica tem na aposentadoria especial de fato um reconhecimento de sua natureza específica, mas indicar que esse fato pode ser um elemento que ajuda a compor o conjunto de especificidades que constrói uma profissão.

A partir desse conjunto de elementos, pode-se afirmar que há pouco debate sobre a questão da aposentadoria no contexto da valorização do magistério, e poucos elementos para entender como os professores percorrem e terminam a carreira docente. $O$ debate sobre 0 caso empírico dos professores do Paraná objetiva fazer uma conexão entre o direito à aposentadoria e a trajetória dos professores na carreira.

\section{Os professores que se aposentam: o caso do Paraná}

Cabe inicialmente algumas observações metodológicas sobre o uso da RAIS e a extração específica dos dados sobre professores aposentados. A RAIS é informada pelos empregadores e considera os vínculos dos trabalhadores, um mesmo professor pode ter mais de um vínculo de contrato a depender da jornada de trabalho. No Paraná há um predomínio de jornadas de 20 horas, porém, esse é um elemento que apresenta muita variação nas condições de trabalho ao considerar-se horas extraordinárias e acúmulo de vínculos em mais de uma rede de ensino.

A extração dos dados da RAIS no sistema online do Ministério do Trabalho não permite a identificação do Cadastro de Pessoa Física (CPF) do trabalhador, por questões de segurança da informação, e por isso não é possível identificar se o mesmo professor atua em mais de uma rede de ensino ou mesmo se tem mais de um vínculo na mesma rede. Portanto, analisa-se aqui a trajetória dos vínculos, o que significa que o professor pode ter se aposentado em um vínculo (ou em uma jornada) e continuar ainda na ativa em outro vínculo na mesma rede, caso tenha feito um segundo concurso público para outra jornada de 20 horas, ou outro tipo de contrato temporário, ou ainda em outra rede de ensino.

Para a análise aqui desenvolvida, considerou-se, em cada ano, os vínculos não ativos em 31 de dezembro de 2008 e de 2016, que tiveram como motivo do desligamento do trabalho 
a aposentadoria ${ }^{1}$. Padronizou-se também que os vínculos tivessem remuneração diferente de zero. Destaca-se que apenas 1\% dos vínculos não ativos em 31 de dezembro apresentaram zero na remuneração. Nesses dois anos não há registro de aposentadorias na rede federal de ensino no Paraná, assim, considerou-se aqui o conjunto de redes municipais ${ }^{2}$ e estadual, portanto, todo o debate se dará em termos de aposentadoria no setor público brasileiro.

A Tabela 1 apresenta o número de vínculos de professores que apresentaram a condição de desligamento por aposentadoria no Paraná em 2008 e 2016. Observe-se um predomínio de professoras no conjunto das redes municipais do estado do Paraná. Nessa dependência administrativa concentra-se a oferta da educação infantil e dos anos iniciais do ensino fundamental - etapas caracterizadas pela docência de um único professor por turma e que admite o ingresso na profissão com a formação de nível médio na modalidade normal.

Tabela 1 - Número de vínculos de professores aposentados no Paraná, por sexo e dependência administrativa

\begin{tabular}{|c|c|c|c|c|c|c|c|c|c|c|}
\hline \multirow{2}{*}{ Dependência Administrativa } & \multicolumn{4}{|c|}{2008} & \multicolumn{5}{c|}{2016} \\
\cline { 2 - 14 } & Masculino & $\%$ & Feminino & $\%$ & Total & Masculino & $\%$ & Feminino & $\%$ & Total \\
\hline Estadual & 113 & 17 & 550 & 83 & 663 & 194 & 16 & 1.037 & 84 & 1231 \\
\hline Municipal & 36 & 4 & 797 & 96 & 833 & 57 & 2 & 2.574 & 98 & 2631 \\
\hline
\end{tabular}

Fonte: Brasil; MTE (2008; 2016).

$\mathrm{Na}$ rede estadual, ainda há maioria de aposentadorias de professoras, porém com uma participação um pouco mais significativa de professores. A rede estadual oferece de forma predominante, no estado do Paraná, os anos finais do ensino fundamental e ensino médio para essas etapas o ingresso dos professores exige a formação em nível superior em cursos de licenciatura. A primeira questão que chama a atenção é o número maior de aposentadorias nas redes municipais em relação à rede estadual, o que pode ter diferentes fatores explicativos, tais como: percentuais de professores temporários, políticas de incentivo à permanência nas redes para quem já completou o tempo mínimo para se aposentar, etc. Questões que mereceriam investigação específica.

Para compreender o perfil dos professores que se aposentaram, e, em que condições da carreira o fizeram, cabe considerar primeiro a formação, idade, tempo de serviço e a jornada de trabalho. A Tabela 2 apresenta o mapa dessas variáveis para os casos das redes estadual e municipais nos anos em discussão. A primeira questão que chama a atenção na Tabela 2 é o tempo de serviço no cargo no momento da aposentadoria. Cabe lembrar aqui que a regra decorrente das Emendas de 2003 e 2004 à Constituição Federal definem que, para o servidor público, é preciso compor os requisitos de 20 anos de serviço público, 15 anos na carreira e 5 anos no cargo ${ }^{3}$ (RAFANHIM, 2012).

Observe-se que os dados da RAIS não indicam que trajetórias o professor teve anteriormente ao cargo em que ele se aposentou, portanto, o que fica evidenciado é que os

1 A RAIS apresenta diferentes opções para identificação de tipo de aposentadoria, porém esse aspecto não foi desdobrado para este artigo.

2 O Paraná tem 399 municípios, portanto, 399 redes municipais de ensino com oferta de educação infantil e anos iniciais do ensino fundamental. A oferta de anos finais do ensino fundamental era feita em 11 cidades em 2008, e, em 2016, apenas em seis cidades, com um número de matrículas bastante reduzido (INEP, 2008; 2016).

3 Em 2005 houve nova Emenda Constitucional (n. 47), estabelecendo regra de transição para os servidores que ingressaram até 1998 no serviço público. 
aposentados, nos dois anos em questão, estão bastante além da exigência mínima, pois o menor tempo médio no cargo foi de 21 anos, no caso de professores e professoras municipais, em 2008, e 23 anos no cargo, no caso de mulheres na rede estadual, em 2016.

Tabela 2 - Número de vínculos de professores aposentados no Paraná, por sexo, tempo de serviço, idade e média de horas de trabalho

\begin{tabular}{|c|c|c|c|c|c|c|c|}
\hline \multirow[b]{2}{*}{$\begin{array}{l}\text { Dependência } \\
\text { administrativa }\end{array}$} & \multirow[b]{2}{*}{ Sexo } & \multicolumn{3}{|c|}{2008} & \multicolumn{3}{|c|}{2016} \\
\hline & & $\begin{array}{l}\text { Tempo de } \\
\text { serviço no } \\
\text { cargo }\end{array}$ & Idade & $\begin{array}{l}\text { Média de } \\
\text { horas de } \\
\text { trabalho } \\
\text { semanal }\end{array}$ & $\begin{array}{l}\text { Tempo de } \\
\text { serviço no } \\
\text { cargo }\end{array}$ & Idade & $\begin{array}{c}\text { Média de horas } \\
\text { de trabalho } \\
\text { semanal }\end{array}$ \\
\hline \multirow{2}{*}{ Estadual } & Masculino & 25 & 60 & 26 & 27 & 61 & 40 \\
\hline & Feminino & 23 & 55 & 24 & 23 & 56 & 40 \\
\hline \multirow{2}{*}{ Municipal } & Masculino & 21 & 58 & 25 & 25 & 57 & 23 \\
\hline & Feminino & 21 & 54 & 24 & 25 & 54 & 23 \\
\hline
\end{tabular}

Fonte: Brasil; MTE (2008; 2016).

No caso da rede estadual, em 2008, foram informadas 663 aposentadorias de professores, todos com formação em ensino superior. Entre estes, os do sexo masculino aposentaram-se em média com 60 anos de idade e 25 anos de serviço. As professoras aposentaram-se em média com 55 anos e 23 anos de trabalho. Em 2016 foram 1.231 aposentadorias de professores com ensino superior, sendo que, destes, 23 possuíam mestrado ou doutorado. Os professores terminaram a carreira com 61 anos de idade em média e 27 anos de trabalho, enquanto as professoras terminaram a carreira em média com 56 anos de idade e 23 anos de trabalho. Há um expressivo aumento na média da jornada de trabalho na rede estadual, o que pode ter relação com uma política de incentivo à jornada de 40 horas, ocorrida em 2009, que unificou os contratos ${ }^{4}$ dos professores em 40 horas semanais:

Essa alteração ocorre, pois no ano de 2009 foi instituído no Paraná o cargo de 40 horas, por meio do Decreto $n^{\circ} 4213$ que regulamentou o artigo 29 da lei complementar 103/04, o Plano de Carreira. Essa regulamentação permitiu que alguns professores que possuíssem 2 cargos de 20 horas ou um cargo de 20 horas e aulas extraordinárias pudessem realizar a dobra de padrão. Essa medida beneficiou cerca de 5000 professores, tendo em vista que esses detinham dois cargos de 20 horas com vencimentos diferentes, já que os dois padrões poderiam estar em lugares distintos na carreira, e o cálculo ocorreu com base no cargo mais antigo (GODOY, 2014, p. 73).

O referido decreto não foi reeditado nos anos seguintes, portanto o procedimento não se tornou regular na rede estadual. A opção pelo cargo mais antigo para agregação dos padrões pode ter ampliado um pouco o número de vínculos com direito à aposentadoria, o que poderia explicar a ampliação bastante expressiva do número de aposentados na rede estadual. Entretanto, para essa análise exigiria conhecer-se mais sobre o fluxo de aposentadorias de professores, tema para o qual não temos estudos acadêmicos no Brasil.

No caso da rede municipal, em 2008 foram 833 aposentadorias, nesse caso $56 \%$ tinham ensino superior, $73 \%$ apresentaram formação de nível médio e $7 \%$ eram professores leigos, ou seja, sem formação mínima exigida na legislação brasileira. Os homens apresentavam idade média de 58 anos e em média 21 anos de serviço. As mulheres aposentaram-se em

4 Cada contrato de 20 horas na rede estadual é denominado "padrão". 
média com 54 anos e 21 anos de tempo de serviço. Em 2016, aposentaram-se 2.631 professores, sendo $87 \%$ destes com ensino superior ou pós-graduação, $12 \%$ com ensino médio e $1 \%$ ainda sem formação. Os professores aposentaram-se com 57 anos de idade e 25 anos de serviço; as professoras, com 54 anos e 25 anos de trabalho.

Os dados sugerem um leve aumento na idade da aposentadoria e evidenciam o aumento do tempo de serviço, o que é esperado devido à consolidação da reforma previdenciária de 2003. Cabe destacar que esse quadro se refere a professores exclusivamente da educação básica, portanto, que trabalham com crianças e adolescentes. Este é um ponto importante para se considerar: que implicações para a qualidade do trabalho a expansão do tempo na ativa terá com eventuais novas mudanças de regras na aposentadoria?

Analisar as condições de carreira em que os professores se aposentaram terá aqui como variável chave o tema da remuneração. A Tabela 3 sintetiza informações gerais sobre a média da remuneração por rede de ensino e sexo do trabalhador; a diferenciação pela variável sexo justifica-se pelas regras diferenciadas de aposentadoria previstas constitucionalmente no Brasil.

Tabela 3 - Média de remuneração de professores aposentados no Paraná no ano de aposentadoria, por sexo e dependência administrativa

\begin{tabular}{|c|c|c|c|c|c|c|c|c|c|c|c|}
\hline \multirow[b]{2}{*}{$\begin{array}{l}\text { Dependência } \\
\text { Administrativa }\end{array}$} & \multirow[b]{2}{*}{ Sexo } & \multicolumn{3}{|c|}{2008} & \multicolumn{3}{|c|}{2016} & \multicolumn{2}{|l|}{2008} & \multicolumn{2}{|c|}{2016} \\
\hline & & $\mathrm{N}$ & $\begin{array}{c}\text { Média } \\
\text { nominal }\end{array}$ & DP & $\mathrm{N}$ & $\begin{array}{l}\text { Média } \\
\text { Nominal }\end{array}$ & $\mathrm{DP}$ & $\begin{array}{c}\text { Média } \\
\text { INPC } 2017\end{array}$ & $\mathrm{DP}$ & $\begin{array}{c}\text { Média } \\
\text { INPC } 2017\end{array}$ & $\mathrm{DP}$ \\
\hline \multirow{2}{*}{ Estadual } & $M$ & 113 & 3.172 & 1.462 & 194 & 6.996 & 3.144 & 5.392 & 2.485 & 7.151 & 3.214 \\
\hline & $\mathrm{F}$ & 550 & 3.019 & 1.450 & 1.036 & 6.511 & 3.025 & 5.133 & 2.466 & 6.655 & 3.092 \\
\hline \multirow{2}{*}{ Municipal } & $M$ & 36 & 1.615 & 2.261 & 56 & 6.162 & 12.518 & 2.746 & 3.843 & 6.298 & 12.795 \\
\hline & $\mathrm{F}$ & 777 & 2.025 & 4.259 & 2.532 & 4.819 & 4.407 & 3.442 & 7.240 & 4.925 & 4.505 \\
\hline
\end{tabular}

Fonte: Brasil; MTE (2008; 2016).

Observe-se que a média de remuneração dos professores no ano em que se aposentaram na rede estadual foi maior do que o conjunto das redes municipais nos dois anos considerados. Porém, não cabe uma conclusão apressada sobre uma desigualdade de gênero comum no mercado de trabalho, pois, nesse caso, ao ter um plano de carreira, os cinco anos exigidos a mais para a aposentadoria podem significar novas progressões, o que exigiria mais investigação. Nos dois casos há um aumento real importante nas médias de remuneração.

Considerando as diferenças de remuneração por sexo, observe-se que, na rede estadual, os homens aposentaram-se com médias de remuneração maiores nos dois anos considerados - o desvio padrão é razoavelmente próximo, o que pode significar que as desigualdades internas nos grupos são similares. No caso das redes municipais, observa-se uma inversão, em 2008 a média de remuneração entre os homens era menor e passou a ser maior em 2016. Todavia, nesse caso, o número de aposentados é bastante reduzido. Nas redes municipais o desvio padrão na média da aposentadoria dos dois grupos considerados é muito grande, indicando que há grande desigualdade interna.

Entre as desigualdades internas, entre os grupos de professores e professoras nas redes estaduais e municipais do Paraná, percebe-se o perfil da qualificação, de forma 
acentuada. A jornada de trabalho também é um elemento muito forte de variação das médias de remuneração em todos os estudos sobre este tema. Assim, para avançar na caracterização, a Tabela 4 apresenta a média de remuneração por hora de trabalho e por formação. O uso da razão entre remuneração média e horas de trabalho permite observar, em uma única medida, as variações desses dois elementos, e permite cotejar de maneira mais direta com as diferenciações por formação do professor. Com esse procedimento, busca-se observar de maneira mais detalhada os elementos que impactam as condições de valorização do professor no momento da aposentadoria.

Dado o volume de variáveis, observa-se agora os dados das redes municipais e estadual em separado. A Tabela 4 dedica-se ao caso da rede estadual. A primeira questão a destacar é que, no ano de 2008, todos os vínculos foram informados com a formação de nível superior. A pós-graduação mais presente entre professores de educação básica é a especialização, porém essa informação não está entre as variáveis de formação coletadas pela RAIS. Isso é em parte problemático, pois o plano de carreira da rede estadual de ensino do Paraná prevê diferença na remuneração entre ensino superior e especialização (GODOY, 2015; GOUVEIA et al., 2017), algo que tem impacto nas médias.

Os dados da RAIS evidenciam, na Tabela 4, a presença de professores com mestrado e doutorado em 2016, ainda que estes sejam um número bastante reduzido: dois professores com mestrado em 2016 e 18 professoras com mestrado e duas professoras com doutorado. Observa-se que a média geral cresce considerando a formação no caso do mestrado, mas não do doutorado.

Tabela 4 - Média de remuneração por hora de professores aposentados na Rede Estadual de Ensino do Paraná, no ano de aposentadoria, por sexo e formação - valores atualizados INPC 2017

\begin{tabular}{|c|c|c|c|c|c|c|c|c|c|}
\hline \multirow{3}{*}{ Sexo } & \multirow{3}{*}{ Formação } & \multicolumn{4}{|c|}{2008} & \multicolumn{4}{|c|}{2016} \\
\hline & & \multicolumn{4}{|c|}{ Remuneração por hora } & \multicolumn{4}{|c|}{ Remuneração por hora } \\
\hline & & Média & Mínimo & $\begin{array}{l}\text { Até } 75 \% \text { dos } \\
\text { vínculos }\end{array}$ & $\begin{array}{l}\text { Até } 95 \% \text { dos } \\
\text { vínculos }\end{array}$ & Média & Mínimo & $\begin{array}{l}\text { Até } 75 \% \text { dos } \\
\text { vínculos }\end{array}$ & $\begin{array}{l}\text { Até } 95 \% \text { dos } \\
\text { vínculos }\end{array}$ \\
\hline \multicolumn{10}{|c|}{ Rede estadual } \\
\hline \multirow{3}{*}{ M } & $\begin{array}{l}\text { Ensino } \\
\text { superior }\end{array}$ & 45 & 18 & 52 & 74 & 39 & 8 & 51 & 70 \\
\hline & Mestrado & & & & & 65 & 52 & 78 & 78 \\
\hline & $\begin{array}{l}\text { Ensino } \\
\text { superior }\end{array}$ & 47 & 10 & 54 & 78 & 37 & 9 & 47 & 71 \\
\hline \multirow[t]{2}{*}{$\mathrm{F}$} & Mestrado & & & & & 43 & 17 & 62 & 71 \\
\hline & Doutorado & & & & & 31 & 20 & 41 & 41 \\
\hline
\end{tabular}

Fonte: Brasil; MTE (2008; 2016).

A Tabela 4 procurou identificar, além da média, o valor mínimo para o grupo e o topo do valor da remuneração por hora, considerando até $75 \%$ dos vínculos de professores e até $95 \%$ do vínculo dos professores. Utilizou-se essa estratégia para isolar casos em que a média de remuneração no momento da aposentadoria tenha sido alterada por pagamento de atrasados ou similares. O uso dos percentis permite observar o ponto que a maioria dos aposentados atingiu em termos salariais. Esse exercício faz mais sentido com o grupo de professores com formação de ensino superior, pois esse é o agrupamento que representa a maior parte dos 
vínculos na rede estadual. Nesse caso, a primeira observação é que, entre 2008 e 2016, os aposentados tiveram perda na média de remuneração quando se considera os valores atualizados pelo INPC. Uma das possibilidades de explicação é que a valorização salarial decorre do plano de carreira, portanto, na média geral há uma valorização, mas ela não é alcançada por todos os professores equitativamente, dependerá da trajetória de cada um no acesso aos níveis finais da carreira.

No caso das redes municipais, há uma variação maior em perfis de formação. Ainda há professores leigos, embora estejam em rápido decréscimo: entre os aposentados, em 2008, estavam quatro professores e 56 professoras, enquanto em 2016 esse número recuou para um professor e 30 professoras. As médias de remuneração por hora nesse caso variam sem nenhuma tendência evidente. Quando se observa a outra ponta, de professores com mestrado e doutorado, novamente há um número muito pequeno de casos, porém com a tendência de crescimento.

Em 2008 havia um professor e uma professora, que chegaram à aposentadoria com formação de mestrado nas redes municipais paranaenses. Em 2016 o número de professores com mestrado foi um, novamente, porém entre as professoras ampliou-se para 56 aposentadas com mestrado e $14 \mathrm{com}$ doutorado. Percebe-se que os dados permitem observar melhor a variação das remunerações entre professores com formação de nível médio e formação de nível superior. No conjunto das redes municipais, a variação no valor da remuneração por hora indica crescimento real na média no período, e esse crescimento é positivo tanto para os casos de formação de ensino médio quanto superior. Quando se compara a média com o valor máximo, que $95 \%$ dos professores que se aposentaram em 2008 atingiu, observa-se que a dispersão era bem mais ampla do que acontece em 2016.

Tabela 5 - Média de remuneração por hora de professores aposentados nas redes municipais de ensino no Paraná, no ano de aposentadoria, por sexo e formação - valores atualizados INPC 2017

\begin{tabular}{|c|c|c|c|c|c|c|c|c|c|}
\hline \multirow{3}{*}{ Sexo } & \multirow{3}{*}{ Formação } & \multicolumn{4}{|c|}{2008} & \multicolumn{4}{|c|}{2016} \\
\hline & & \multicolumn{4}{|c|}{ Remuneração por hora } & \multicolumn{4}{|c|}{ Remuneração por hora } \\
\hline & & Média & Mínimo & $\begin{array}{l}\text { Até } 75 \% \text { dos } \\
\text { vínculos }\end{array}$ & $\begin{array}{l}\text { Até } 95 \% \text { dos } \\
\text { vínculos }\end{array}$ & Média & Mínimo & $\begin{array}{l}\text { Até } 75 \% \text { dos } \\
\text { vínculos }\end{array}$ & $\begin{array}{l}\text { Até } 95 \% \text { dos } \\
\text { vínculos }\end{array}$ \\
\hline \multirow{4}{*}{ M } & Leigo & 10 & 4 & 14 & 17 & 23 & 23 & 23 & 23 \\
\hline & $\begin{array}{l}\text { Ensino } \\
\text { médio }\end{array}$ & 22 & 5 & 27 & 82 & 23 & 9 & 28 & 33 \\
\hline & $\begin{array}{l}\text { Ensino } \\
\text { superior }\end{array}$ & 35 & 8 & 23 & 215 & 71 & 9 & 76 & 133 \\
\hline & Mestrado & 20 & 20 & 20 & 20 & 95 & 95 & 95 & 95 \\
\hline \multirow{5}{*}{$\mathrm{F}$} & Leigo & 17 & 1 & 18 & 47 & 33 & 8 & 30 & 157 \\
\hline & $\begin{array}{l}\text { Ensino } \\
\text { médio }\end{array}$ & 20 & 4 & 24 & 46 & 35 & 4 & 35 & 76 \\
\hline & $\begin{array}{l}\text { Ensino } \\
\text { superior }\end{array}$ & 44 & 6 & 38 & 107 & 54 & 4 & 64 & 117 \\
\hline & Mestrado & 9 & 9 & 9 & 9 & 43 & 8 & 51 & 111 \\
\hline & Doutorado & & & & & 59 & 9 & 113 & 146 \\
\hline
\end{tabular}

Fonte: Brasil; MTE (2008; 2016). 
Quem são os professores que chegam à aposentadoria?

O caso das redes municipais incorpora um outro elemento de desigualdade interna, os dados são médias de remuneração que resultam de diferentes carreiras. Isso pode justificar uma variação interna entre os dados das redes municipais. De toda forma é visível a valorização da hora da remuneração para professores com ensino superior.

\section{Considerações finais}

Considerando a natureza relacional do trabalho docente e, especialmente, que a intensidade dessa relação faz "[...] a personalidade do professor tonar-se uma parte integrante da interação e é absorvida pelo trabalho" (TARDIF; LESSARD, 2014, p. 279), merece atenção e discussão mais ampla as mudanças previdenciárias que levam ao aumento contínuo da idade dos professores em exercício nas redes e os efeitos desse processo nos limites e nas possiblidades do trabalho docente.

Ao longo da revisão dos conceitos, no intuito de se compor um quadro sobre o lugar da aposentadoria no debate sobre profissionalização e valorização docente, encontrou-se uma dubiedade entre um direito à aposentadoria que pode compor a defesa da natureza específica da profissão, e, em decorrência disso pode reforçar o sentido de profissionalização, e também, com muita força, encontrou-se elemento de uma construção histórica da aposentadoria especial como uma compensação por uma profissão com insuficientes condições de reconhecimento e exercício profissional, especialmente na educação básica. Não parece possível fugir dessa dubiedade, por isso, ao recorrer a Tardif e Lessard (2014), importa considerar que há uma natureza específica na docência que mobiliza, de "corpo e alma", o sujeito docente, e essa compreensão permite problematizar os efeitos que as regras na aposentadoria provocam no desenvolvimento das carreiras docentes.

O que os dados analisados a partir da RAIS, para o caso do Paraná, permitem concluir é que os professores chegam à aposentadoria com as marcas de trajetórias individuais. Essas trajetórias decorrem de elementos que valorizam a remuneração dos professores no desenho geral das carreiras, permitindo observar-se crescimento geral na média das remunerações, mas não garante igualdade de condições de aposentadoria quando observamos os subgrupos de professores por formação. Isso fica muito fortemente evidenciado com a comparação na remuneração por hora entre 2008/2016 dos professores e professoras por nível de formação. Os resultados indicam que os professores tiveram perda na remuneração quando possuem a mesma formação inicial, ou seja, os ganhos nas médias são ganhos de trajetórias individuais. As formas de acesso à qualificação em pós-graduação não são universais, e o dilema dos congelamentos ou simples descumprimento de planos de carreira ampliam a diferença entre a promessa de valorização e a efetivação desse princípio constitucional.

Outra conclusão possível, a partir da leitura dos dados da RAIS sobre aposentadoria de professores da educação básica, é a de que as mudanças decorrentes das emendas constitucionais em 2003 e 2004 têm adiado a aposentadoria de professores. Ou seja, são mudanças efetivas no perfil dos aposentados, mas que são efetivas também no perfil dos profissionais que estão na ativa, pois estão a permanecer mais tempo no exercício profissional. Se a perspectiva que se adota é a de que a docência é uma profissão de uma intensidade tal de relações que a própria personalidade do professor se torna parte do trabalho, é preciso urgentemente conhecer melhor os efeitos que esse processo de extensão do tempo ativo na carreira tem em relação à saúde docente, à qualidade do trabalho na 
Quem são os professores que chegam à aposentadoria?

relação com crianças, adolescentes e jovens. Sem responder a essas questões parece precoce qualquer debate sobre reforma da previdência que altere as condições do magistério.

$\mathrm{O}$ artigo pretendeu deixar em evidência que há um desafio acadêmico de pensar a aposentadoria como um elemento de debate sobre a profissão docente, assim como um desafio político de diagnóstico dos efeitos da legislação sobre um grupo específico de trabalhadores.

\section{Referências}

BECKER, Kalinca Léia; KASSOUF, Ana Lúcia. Diferença salarial e aposentadoria dos professores do ensino fundamental. Economia Aplicada, Ribeirão Preto, v. 16, n. 1, p. 77-104, 2012.

BRASIL. Constituição Federal. Diário Oficial da União, Brasília, 1988. Disponível em: <http://www.planalto.gov.br/ccivil_03/constituicao/>. Acesso em: 02 maio 2018.

BRASIL. MTE. Ministério do Trabalho e Emprego. Relação Anual de Informações Sociais (RAIS). Microdados, 2008. Brasília, 2008. Disponível em: <ftp://ftp.mtps.gov.br/ pdet/microdados/RAIS/2008/>. Acesso em: 31 jan. 2018.

BRASIL. MTE. Ministério do Trabalho e Emprego. Relação Anual de Informações Sociais (RAIS). Microdados, 2016. Brasília, 2016. Disponível em: <ftp://ftp.mtps.gov.br/pdet/ microdados/RAIS/2016/>. Acesso em: 31 jan. 2018.

BRASIL. MTE. Ministério do Trabalho e Emprego. Relação Anual de Informações Sociais (RAIS). Brasília, 2018. Disponível em: <http://pdet.mte.gov.br/o-que-e-rais>. Acesso em: 31 jan. 2018.

BRASIL. Presidência da República. Emendas Constitucionais. 2019. Disponível em: <http://www.planalto.gov.br/ccivil_03/constituicao/emendas/emc/quadro_emc.htm>. Acesso em: 02 maio 2018.

CASSETTARI, Nathalia. Remuneração variável para professores: revisão de literatura e desdobramentos no Estado de São Paulo. 2010. Dissertação (Mestrado em Educação) Programa de Pós-Graduação em Educação, Universidade de São Paulo, São Paulo, 2010.

FERNANDES, Maria Dilnéia Espíndola; GOUVEIA, Andrea Barbosa; BENINI, Élcio Gustavo. Remuneração de professores no Brasil: um olhar a partir da Relação Anual de Informações Sociais (RAIS). Educação e Pesquisa, São Paulo, USP, v. 38, p. 339-356, 2012.

FERREIRA Jr., Amarílio. A Confederação dos Professores do Brasil e a aposentadoria aos 25 anos. In: GINDIN, Julián; FERREIRA, Márcia Ondina Vieira; DAL ROSSO, Sadi (Org.). Associativismo e sindicalismo em educação: teoria, história e movimentos. 1. ed. Brasília: Paralelo 15, 2013. v. 2. P. 151-165.

GATTI, Bernadete; BARRETO, Elba. Professores do Brasil: impasses e desafios. Brasília: UNESCO, 2009.

GODOY, Marina de. Condições de carreira e remuneração dos professores no Estado do Paraná (2005-2012). 2014. Dissertação (Mestrado em Educação) -Programa de PósGraduação em Educação, Universidade Federal do Paraná, Curitiba, 2014.

GOUVEIA, Andréa Barbosa et al. Remuneração de Professores de Escolas Públicas de Educação Básica no Contexto do Fundeb e do PSPN. Relatório Estadual - Paraná. Curitiba: UFPR, 2017. 
Quem são os professores que chegam à aposentadoria?

GROCHOSKA, Marcia Andréia. Políticas educacionais e a valorização do professor: carreira e qualidade de vida dos professores de educação básica do município de São José dos Pinhais/PR. 2015. Tese (Doutorado em Educação) - Universidade Federal do Paraná, Curitiba, 2015.

HARRYS, Debbi C. The Promises and Pitfalls of Alternative Teacher Compensation Approaches. Colorado/EUA: EPIC; APRU, 2007.

INEP. Instituto Nacional de Estudos e Pesquisas Educacionais Anísio Teixeira. Consulta à matrícula. Censo Escolar 2008. Brasília, 2008. Disponível em: <http://inep.gov. br/censoescolar>. Acesso em: 02 maio 2018.

INEP. Instituto Nacional de Estudos e Pesquisas Educacionais Anísio Teixeira. Consulta à matrícula. Censo Escolar 2016. Brasília, 2016. Disponível em: <http://inep.gov.br/ censoescolar>. Acesso em: 02 maio 2018.

MORDUCHOWICZ, Alejandro. Carreiras, Incentivos e Estruturas Salariais Docentes. Programa de Promoção da Reforma Educativa na América Latina e Caribe. Junho, 2003.

OCDE; UNESCO. Education at a Glance 2017: OECD Indicators. Paris: OECD Publishing, 2017. Disponível em: <http://dx.doi.org/10.1787/eag-2017-en>. Acesso em: 31 jan. 2018.

OLIVEIRA, Dalila Andrade. Os trabalhadores docentes e a construção política da profissão docente no Brasil. Educar em Revista, Curitiba, v. n.1, p. 17-36, 2010.

RAFANHIM, Ludimar. Decisões Judiciais e Valorização dos Profissionais do Magistério. 2012. Dissertação (Mestrado em Educação) - Programa de Pós-Graduação em Educação, Universidade Federal do Paraná, Curitiba, 2012.

RAFANHIM, Ludimar. Planos de Carreira dos Servidores Públicos depois da Reforma Previdenciária de 2003. Revista L\&C, 2013.

SOUZA, Ângelo Ricardo de; ABREU, Diana Cristina. Ingresso na carreira docente: As experiências de Brasil e Chile. Archivos Analíticos de Políticas Educativas / Education Policy Analysis Archives, Arizona, v. 24, p. 72-92, 2016.

TARDIF, Maurice; LESSARD, Claude. O trabalho docente: elementos para uma teoria da docência como profissão de interações humanas. 9. ed. Petrópolis: Vozes, 2014.

TENTI FANFANI, Emilio. La condición docente: Analisis comparado de Argentina, Brasil, Perú y Uruguay. Argentina: Século XXI Editores Argentina, 2005.

Andréa Barbosa Gouveia é professora do curso de Pedagogia da Universidade Federal do Paraná (UFPR) e do programa de pós-graduação em educação na mesma universidade. Atua no Núcleo de Pesquisa em Políticas Educacionais.

ORCID: http://orcid.org/0000-0002-8260-2720

E-mail: andrea-gouveia@uol.com.br 


\section{Editores do volume 9}

José Marcelino de Rezende Pinto - Universidade de São Paulo, São Paulo/SP, Brasil

Nalú Farenzena - Universidade Federal do Rio Grande do Sul, Porto Alegre/RS, Brasil

\section{Comitê Editorial}

José Marcelino de Rezende Pinto - Universidade de São Paulo, Brasil

Juca Gil - Universidade Federal do Rio Grande do Sul, Brasil

Theresa Adrião - Universidade Estadual de Campinas, Brasil Ângelo

Ricardo de Souza - Universidade Federal do Paraná, Brasil

Márcia Aparecida Jacomini - Universidade Federal de São Paulo, Brasil

\section{Conselho Editorial}

\section{Alejandro Morduchowicz}

Universidad Pedagógica, Provincia de Buenos Aires, Argentina

Fernanda Saforcada

Universidade de Buenos Aires, Argentina

Jacques Velloso

Universidade de Brasília, Brasil

João Monlevade

Senado Federal, Brasil

Jorge Abrahão de Castro

Instituto de Pesquisa Econômica Aplicada / IPEA, Brasil

Juca Gil

Universidade Federal do Rio Grande do Sul, Brasil

Lisete Regina Gomes Arelaro

Universidade de São Paulo, Brasil

Luis Carlos Sales

Universidade Federal do Piauí, Brasil

Luiz de Sousa Junior

Universidade Federal da Paraíba, Brasil

Luiz Fernandes Dourado

Universidade Federal de Goiás, Brasil

Magna França

Universidade Federal do Rio Grande do Norte, Brasil

\section{Maria Beatriz Luce}

Universidade Federal do Pampa, Brasil

Universidade Federal do Rio Grande do Sul, Brasil

Marcos Edgar Bassi

Universidade Federal de Santa Catarina, Brasil

\author{
Maria Dilnéia Espíndola Fernandes \\ Universidade Federal de Mato Grosso do Sul, Brasil \\ Nalú Farenzena \\ Universidade Federal do Rio Grande do Sul, Brasil \\ Nelson Cardoso do Amaral \\ Universidade Federal de Goiás, Brasil \\ Nicholas Davies \\ Universidade Federal Fluminense, Brasil \\ Rosana Evangelista Cruz \\ Universidade Federal do Piauí, Brasil \\ Rosana Gemaque \\ Universidade Federal do Pará, Brasil \\ Robert E. Verhine \\ Universidade Federal da Bahia, Brasil \\ Romualdo Portela de Oliveira \\ Universidade de São Paulo, Brasil \\ Theresa Adrião \\ Universidade Estadual de Campinas, Brasil \\ Tristan McCowan \\ University of London, Reino Unido \\ Vera Jacob \\ Universidade Federal do Pará, Brasil \\ Vera Peroni \\ Universidade Federal do Rio Grande do Sul, Brasil \\ Vitor Henrique Paro \\ Universidade de São Paulo, Brasil
}

\section{Equipe editorial}

Apoio ao Comitê Editorial: Patrícia Balthazar Garcia

Diagramação, Revisão de português e normalização: Edson Leonel de Oliveira

Revisão de inglês: Ananyr Porto Fajardo 